\title{
A (re)formulação de Tarefas de Investigação Matemática
}

\section{The (re)formulation of Mathematical Research Tasks}

\author{
Paulo Wichnoski \\ Universidade Estadual do Oeste do Paraná - (UNIOESTE) \\ Tiago Emanuel Klüber
}

Universidade Estadual do Oeste do Paraná - (UNIOESTE)

\begin{abstract}
Resumo
Enfocamos neste artigo a (re)formulação de tarefas de matemática em tarefas de Investigação Matemática, interrogando quais aspectos se mostram relevantes nesta ação. Para isso buscamos enunciar algumas perspectivas de reformulação assentando-nos nas ideias de Butts (1997). Recorrendo a dois exemplos desejamos oferecer ao professor de matemática um aporte teórico para a construção ou reformulação nesse contexto. Destacamos que os encaminhamentos de fomentar conjecturas e perguntas que conduzam a mais de uma resposta, desprover o enunciado de informações, inverter a ordem do problema inicial, evitar prescrições demasiadamente diretivas e evitar o uso de conceitos herméticos e específicos da área, são essenciais à reformulação.
\end{abstract}

Palavras-chave: Reformulação de problemas; Investigação Matemática; Ensino de Matemática.

\begin{abstract}
We focus on this article the (re)formulation of mathematical tasks in Mathematical Research tasks, asking which aspects are relevant in this action. For this, we seek enunciate some reformulation perspectives based on the ideas of Butts (1997). Using two examples we wish offer the mathematics teacher a theoretical contribution to the construction or reformulation in this context. We emphasize as essential referrals to the reformulation, foment the conjectures and questions that lead to more than one answer, deprive the statement of information, reverse the order of the initial problem, avoid overly directive prescriptions and avoid the use of hermetic and specific concepts of the area, are essential to reformulation.
\end{abstract}

Keywords: Reformulation of Problems; Mathematical Research; Mathematics Teaching.

\section{Sobre A Motivação Do Trabalho}

A (re)formulação de tarefas tidas como corriqueiras nas aulas de matemática em tarefas de Investigação Matemática caracteriza-se como um avanço teórico neste campo da Educação Matemática. Além disso, é uma habilidade necessária ao professor que, porventura, deseja trabalhar com a Investigação Matemática em sala de aula, dado a pouca presença de tarefas construídas sob essa perspectiva nos livros didáticos, conforme relatado por Junkerfuerbon e 
Klüber (2017).

Suscitar tal habilidade depende, dentre outros aspectos, do fazer constante e talvez uma das primeiras dificuldades que se apresenta ao professor é a do como fazer, uma vez que pode não the ser corriqueiro desenvolver modos específicos de abordar e planejar o trabalho investigativo. Esse aspecto indica a necessidade de empreender estudos que teorizam sobre possíveis modos de (re)formular tarefas de Investigação Matemática, bem como estudos que lhes sirvam de aporte em tal empreendimento.

Frente a isso propomos, neste trabalho, teorizar, com recurso a exemplos, sobre a (re)formulação de tarefas matemáticas em tarefas de Investigação Matemática para que ele venha, em suas devidas proporções, a amparar aqueles que queiram assumir práticas de construção ou adaptação dessas tarefas em suas práticas pedagógicas.

Essa teorização emergiu, primeiramente, da necessidade por nós sentida ao nos depararmos, em situações práticas, com a ausência dessas tarefas na maioria dos livros didáticos da tradição brasileira. Essa ausência se confirma de modo sistematizado no trabalho de Junkerfuerbon e Klüber (2017), os quais relatam que "o número de tarefas de Investigação Matemática presentes nos livros é pequeno, quase inexpressivo" (JUNKERFUERBON; KLÜBER, 2017, p. 12). Surgiu também de investigações ${ }^{1}$ que tinham como um dos seus objetivos reconhecer, caracterizar e construir tarefas de Investigação Matemática.

Nesse itinerário, em seis anos subsequentes ${ }^{2}$, aprofundamos os aspectos que emergiram e que ainda não tinham sido escrutinados. Posteriormente, inspirados no texto de Butts (1997), decidimos sintetizar o debate e explicitar algumas perspectivas para a reformulação de tarefas matemáticas que, segundo Butts (1997, p.33), subdividem-se em "exercícios de reconhecimento, exercícios algorítmicos, problemas de aplicação, problemas de pesquisa aberta, situações-problema”, em tarefas de Investigação Matemática.

Além disso, Winch, Wichnoski e Santos (2016) evocam que a pesquisa e prática pedagógica se colocam como possíveis caminhos para repensar e reconfigurar o ensino de matemática. Segundo os autores

$\mathrm{O}$ primeiro diz respeito às inquirições e reflexões amparadas por um procedimento metodológico e sistemático, visando à descoberta de novos conhecimentos. O segundo é aquele que proporciona através do fazer, a possibilidade de reorientar as práticas docentes, as práticas discentes, bem como as práticas de ensino, promovendo gradativamente uma mudança de

\footnotetext{
${ }^{1}$ Monografia intitulada “Atividades de Investigação Matemática a Partir do Banco de Questões da Olimpíada Brasileira das Escolas Públicas - OBMEP”, seguida de um Projeto de Iniciação Científica, na modalidade ICV/Unioeste/PRPPG, intitulado "Investigações Matemáticas na Educação Matemática: teoria e atividades".

${ }^{2}$ No ano de 2012 demos início aos estudos sobre a Investigação Matemática no contexto da Educação Matemática.
} 
concepção acerca do ensino de matemática [...] havendo a possibilidade da realização de um a partir da realização do outro, e vice-versa (WINCH; WICHNOSKI; SANTOS, 2016, p.1-2).

Neste sentido é que desenvolvemos este trabalho, voltando-nos à prática de (re)formulação de tarefas matemáticas em tarefas de Investigação Matemática, interrogando-a e buscando um nível de compreensão e abstração mais elevado.

Destacamos que as perspectivas ora apresentadas não se constituem em receitas ou prescrições definitivas, mas em diretrizes mais ou menos razoáveis que conferem ao (re)formulador alguma segurança. Ainda, a intuição matemática num sentido fenomenológico, deve ser levada em consideração, pois sem a compreensão dos invariantes matemáticos essenciais não é possível destacar os elementos que descortinam as possibilidades investigativas.

Do pensar fenomenológico, a intuição dessas essências se dá por meio de três níveis: lados, aspectos e perfis. Os lados dizem daquilo é mais estável e não se modifica sobre o objeto de conhecimento visado. Os aspectos se referem àquilo que se modifica conforme a "posição do observador", mas que com um auxílio comunicativo e intersubjetivo podem chegar a um acordo e o compreenderem de modo mais pleno. E os perfis concernem à esfera completamente subjetiva e que dificilmente pode ser comunicada ou compartilhada, admitindo-se a idiossincrasia que se instaura em cada uma (SOKOLOWSKI, 2004).

Esse entendimento indica que há tarefas que podem ser vistas com bastante estabilidade por diferentes (re)formuladores, há outras que carecerão de um esforço comunicativo para a compreensão mais plena e, por fim, há algumas que serão inicialmente vistas apenas pelo (re)formulador e poderão nem chegar a se concretizar. Assim é o itinerário da produção de conhecimento e este é o convite deste artigo: tornar o professor um produtor de conhecimento. Ao mesmo tempo é desafio, porque nos retira de uma situação confortável e nos coloca em marcha para a superação de uma visão meramente tecnicista ou simplesmente pragmática da educação.

Este preâmbulo justifica a produção deste artigo e nos remete a explicitar, sem pretensões exaustivas, a nossa compreensão sobre as tarefas de Investigação Matemática e sobre a perspectiva de reformulação de problemas de Butts (1997), relida para o nosso contexto.

\section{Sobre As Tarefas De Investigação Matemática}

O termo tarefa pode ser compreendido como uma expressão na forma de questões, 
problemas, investigações, exercícios, projetos e construções. Todavia, no contexto investigativo, as tarefas assumem características que as particularizam, portanto, a definição acima já não nos serve na sua totalidade. É necessário refinar o seu entendimento e para isso valemo-nos de alguns significados postos na literatura sobre o tema.

Para Ponte (2003) uma tarefa possui quatro dimensões básicas: 1) grau de dificuldade, 2) estrutura, 3) contexto referencial e 3) tempo requerido para a sua resolução. Segundo o autor supracitado, tarefas com estrutura aberta e grau de dificuldade fácil são denominadas de tarefas de exploração ou exploratórias e tarefas com um a estrutura aberta e grau de dificuldade difícil são ditas tarefas de investigação ou investigativas. É importante ressaltar que "O grau de dificuldade, não se dá somente pela tarefa em si, mas também, pelo como o aluno a recepciona" (PINHEIRO, 2013, p. 51), portanto é no mínimo arriscado fazer uma classificação nesse sentido. Este risco é reconhecido pelo próprio autor que afirma:

Muitas vezes não se distingue entre tarefas de investigação e de exploração, chamando-se "investigações" a todas elas. Isso acontece, muito provavelmente, porque é complicado saber à partida qual o grau de dificuldade que uma tarefa aberta terá para um certo grupo de alunos (PONTE, 2003, p. $5)$.

Ainda no domínio da classificação - exploratória e investigativa -, Gravina e Santarosa (1999) atribuem às tarefas do tipo exploratórias uma estrutura enunciativa que sugere algumas atitudes para nortear procedimentos, conjecturas e validações, as quais são apresentadas aos alunos "como um modelo já pronto, o qual dever ser explorado, compreendido e analisado (GRAVINA; SANTAROSA, 1999, p. 81). Em síntese, as tarefas exploratórias contêm em seu enunciado as conjecturas necessárias à investigação de um problema posto.

As tarefas investigativas são para Ponte et al. (1998, p. 9) "actividades de cunho muito aberto, referentes a contextos variados (embora com predominância para os exclusivamente matemáticos) que podem ter como ponto de partida uma questão ou uma situação proposta, quer pelo professor, quer pelos alunos".

Em sentido lato, as tarefas de Investigação Matemática são expressões concretas, estruturadas com certo grau de abertura de modo que o pensamento matemático seja construído nas relações que se estabelecem para com elas de modo investigativo, diferindo, para fins de classificação, de acordo com a abertura da estrutura enunciativa: menor abertura (tarefas exploratórias) maior abertura (tarefas investigativas).

Independentemente de serem exploratórias ou investigativas, as tarefas de Investigação Matemática são plurais e possuem naturezas diversas e estilos variados (WICHNOSKI; KLÜBER, 2015), o que faz com que se abra 
um leque de exploração que vai além de uma única forma de proceder. Há tarefas que permitem explorar conceitos, outras que permitem encontrar resultados e propriedades matemáticas e outras que abrem a possibilidade de o conceito emergir dela própria (WICHNOSKI; KLÜBER, 2015, p. 78).

Em face disso, abrimo-nos à possibilidade de assumir como tarefas de Investigação Matemática não somente aquelas que possuem o estilo conjectura-teste-demonstração (PONTE, 2013), mas também aquelas que num processo de inquirição e confrontos permitam a construção do conhecimento matemático (ensinar/aprender matemática) além da descoberta de fatos matemáticos e técnicas como, por exemplo, as demonstrações.

Explicitados os argumentos sobre os quais se assenta o nosso entendimento de tarefas de Investigação Matemática, na próxima seção, descrevemos a perspectiva de reformulação de problemas matemáticos considerada para este trabalho.

\section{Sobre A Formulação Ou Reformulação De Problemas Matemáticos}

Butts (1997), ao discorrer sobre as perspectivas de reformulações, dirige-se a diferentes tipos de problemas ${ }^{3}$ matemáticos nomeados por ele como: exercícios de reconhecimento, exercícios algorítmicos, problemas de aplicação, problemas de pesquisa aberta e situaçõesproblema. O quadro abaixo, síntese de nossa compreensão, explicita as diferenças entre eles.

\begin{tabular}{|c|c|}
\hline Tipo de problemas matemático & Síntese \\
\hline Exercícios de reconhecimento & $\begin{array}{l}\text { Com estrutura enunciativa bem definida, este tipo } \\
\text { de problema matemático requer o uso de } \\
\text { conceitos (definição, propriedades, teoremas) já } \\
\text { aprendidos para a sua resolução. Exemplos são os } \\
\text { problemas matemáticos de reconhecimento, de } \\
\text { verdadeiro ou falso. }\end{array}$ \\
\hline Exercícios algorítmicos & $\begin{array}{l}\text { São exercícios que podem ser resolvidos via } \\
\text { algoritmo. Há, de antemão, um método para a sua } \\
\text { resolução. Exemplos são os problemas } \\
\text { matemáticos com enunciados do tipo calcule, } \\
\text { efetue as operações. }\end{array}$ \\
\hline Problemas de aplicação & $\begin{array}{l}\text { São problemas que possuem uma pergunta bem } \\
\text { definida, requerem uma resposta única e } \\
\text { envolvem o tratamento dos dados seguido de um } \\
\text { algoritmo. Exemplos são os problemas do tipo: } \\
\text { João tem } 13 \text { figuras e ganhou mais } 11 \text { do seu } \\
\text { amigo. Quantas figuras João possui? }\end{array}$ \\
\hline Problemas de pesquisa aberta & $\begin{array}{l}\text { Com estrutura enunciativa aberta este tipo de } \\
\text { problemas não dispõe, de antemão, uma } \\
\text { estratégia de resolução. Exemplos são os } \\
\text { problemas matemáticos que possibilitam } \\
\text { encontrar regularidades e padrões. }\end{array}$ \\
\hline
\end{tabular}

\footnotetext{
${ }^{3}$ Entendemos este termo como sinônimo de tarefa, enquanto expressões concretas que prescrevem o trabalho a ser realizado. Todavia, nesta seção faremos alusão ao termo problema para manter a fidedignidade às ideias do autor estudado.
} 


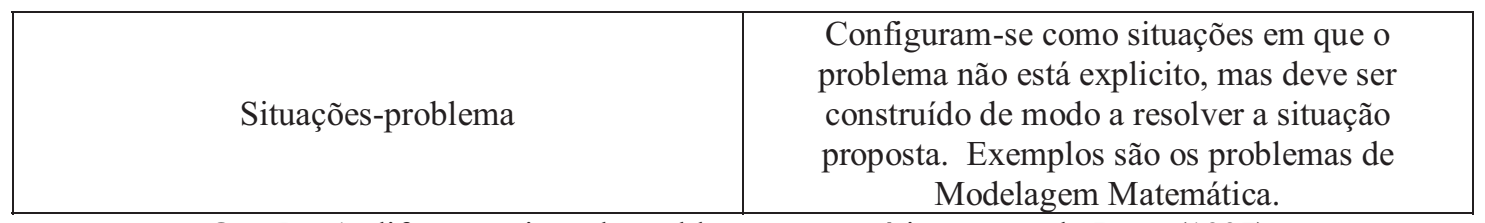

Quadro 1: diferentes tipos de problemas matemáticos segundo Butts (1997). Fonte: os autores.

Entendemos que os problemas (tarefas) de Investigação Matemática se alinham às ideias dos problemas de pesquisa aberta e por isso consideramos possível pensar a sua reformulação, com algum grau de similaridade às perspectivas propostas por Butts (1997). O autor apresenta algumas sugestões de reformulação para os quatro primeiros tipos de problemas matemáticos e evoca que para o quinto tipo a ideia-chave "é identificar os problemas que usualmente recaem nas categorias de aplicação e pesquisa aberta" (BUTTS, 1997, p.37).

Ainda que as tarefas de Investigação Matemática possam ser vistas como parte da categoria de problemas de pesquisa aberta, aventamos a possibilidade de tomar as sugestões de reformulação dadas aos demais tipos, uma vez que, segundo Butts (1997), algumas sugestões se aplicam a vários tipos de problemas e a classificação efetuada por ele tem em vista a categoria de maior impacto, sem exclusividade.

Em outras palavras, as fronteiras entre exercícios de reconhecimento, exercícios algorítmicos, problemas de aplicação, problemas de pesquisa aberta e situações-problema não são bem definidas e excludentes podendo, inclusive, se sobreporem. Assim sendo, há características comuns a vários tipos de problemas e também características individuais. Estas últimas, à medida que aparecem de modo profuso, classificam o problema na categoria de maior impacto.

A primeira ideia trazida por Butts (1997) é desprover o enunciado de alguma estratégia que possibilite a resolução do problema. Isto impõe ao problema um nível maior de abstração. Além disso, é preciso incentivar a conjectura, enquanto função mais importante deste tipo de problema. Segundo o autor "O axioma fundamental sobre formulação de problemas de pesquisa aberta é: Proponha o problema de uma maneira que requeira do resolvedor conjecturar a solução" (BUTTS, 1997, p.42).

A concisão não necessariamente deve estar presente em problemas de pesquisa aberta e o uso de exemplos ilustrativos potencializa a resolução. Com isso o autor adverte que a expressão, prove que e suas variações, não incentivará a conjectura. Perguntar é outra regra que se impõe nos problemas de pesquisa aberta e pode ser usada antes de iniciar a tarefa propriamente dita. É necessário encorajar a pergunta do tipo e se..?

Como sugestão para os problemas algorítmicos Butts (1997) oferece duas ideias: a 
primeira refere-se à generalização e a segunda à inversão do problema. Do nosso entendimento, a primeira ideia pode ser usada de modo análogo em tarefas de Investigação Matemática que buscam a generalização, ou nas palavras de Ponte et al. (2013) nas tarefas que possuem o estilo conjectura-teste-demonstração.

A segunda ideia pode ser utilizada em tarefas que objetivam tratar o conteúdo matemático durante o desenvolvimento da atividade, enquanto tarefas que possibilitam o ensino de um conhecimento matemático novo para os alunos. Obviamente que ao final do processo de generalização e consequentemente demonstração haverá a produção de um fato novo, todavia alguns conceitos e ideias matemáticas não emergem via processos de demonstração, como por exemplo, o conceito basilar de função.

Em face do que é proposto por Butts (1997) e dos modos específicos de (re)formulação que temos desenvolvido enquanto professores e pesquisadores adeptos à Investigação Matemática, indicamos no quadro abaixo algumas sugestões para nortear a prática de (re)formulação de tarefas matemáticas em tarefas de Investigação Matemática.

\begin{tabular}{|c|l|}
\hline 1 & Eliminar ou evitar perguntas que obtenham uma única resposta \\
\hline 2 & Evitar processos demasiadamente prescritivos ou concisos \\
\hline 3 & Evitar o uso de conceitos herméticos e específicos da área \\
\hline 4 & Estabelecer condições prévias para o entendimento do que a situação pede \\
\hline 5 & Estabelecer perguntas que permitam a construção de conjecturas \\
\hline 6 & Apresentar de modo ‘invertido’ o problema que gerou a situação (transformar a \\
\hline 7 & resolução do problema no enunciado da tarefa) \\
\hline 8 & Construir roteiros abertos \\
\hline 9 & Construir roteiros semiabertos \\
\hline 10 & Fomentar a generalização \\
\hline 11 & Retirar informações \\
\hline 12 & Desprover o enunciado de contextualização cotidiana e outras \\
\hline
\end{tabular}

Quadro 2: sugestões para a (re)formulação de tarefas de Investigação Matemática. Fonte: os autores.

Advertimos para a possibilidade de existirem outras perspectivas que não foram aqui explicitadas. As ideias apresentadas são oriundas de um movimento interpretativo próprio dos autores deste texto e, portanto, não são acabadas e únicas. Além disso, elas admitem flexibilidade dependendo do objetivo que se pretende com a tarefa, bem como do contexto para o qual se dirige. Por exemplo, se o objetivo é ensinar o Teorema de Pitágoras, há a possibilidade de fomentar a generalização, disparar perguntas que visam à construção de conjecturas e, por fim, demostrar a validade deste resultado. Agora, se o objetivo é ensinar o conceito de função, 
a generalização e construção de conjecturas não encontram espaço nas tarefas a serem propostas, uma vez "que o conceito em si não é demonstrável. O que é demonstrável são os resultados e as propriedades que derivam do conceito" (WICHNOSKI; KLÜBER, 2015, p.76).

Deste quadro teórico, a próxima seção cumpre o objetivo de traduzir o esforço efetuado para (re)formular problemas (tarefas) tidas como corriqueiras em tarefas de Investigação Matemática. Recorremos a dois exemplos sem nos preocupar com a classificação, tipo e estilo postos pela literatura, haja vista que o nosso objeto é tão somente explicitar as perspectivas que nortearam as suas transformações.

\section{Exemplificando As Perspectivas De (Re)Formulação}

\section{Exemplo 1}

Sabendo que num estacionamento há 32 rodas entre carros e motos e um total de 11 veículos, quantas motos e quantos carros há?

Este problema é habitualmente resolvido por um sistema de equações lineares e com alguns métodos algébricos clássicos como, por exemplo, o método da adição, da substituição e escalonamento. Para isso é preciso traduzir o problema em linguagem proposicional e em seguida aplicar o método. Alguns métodos mais construtivos sugerem aos alunos a construção de uma tabela de valores para identificar a única solução possível, como segue:

\begin{tabular}{|c|c|c|c|}
\hline Carros+Motos & Rodas Carros & Rodas Motos & Total de Rodas \\
\hline $1+10$ & 4 & 20 & 24 \\
\hline $2+9$ & 8 & 18 & 26 \\
\hline $3+8$ & 12 & 16 & 28 \\
\hline $4+7$ & 16 & 14 & 30 \\
\hline $5+6$ & 20 & 12 & 32 \\
\hline $6+5$ & 24 & 10 & 34 \\
\hline $7+4$ & 28 & 8 & 36 \\
\hline $8+3$ & 32 & 6 & 38 \\
\hline $9+2$ & 36 & 4 & 40 \\
\hline $10+1$ & 40 & 2 & 42 \\
\hline
\end{tabular}

Tabela 1: possível solução do problema.

Fonte: os autores.

Note-se que esse tipo de problema foi criado com a intenção da apresentação de um método de solução linear, que indica uma única solução. Esse é um essencial a ser considerado na reformulação. É um problema algébrico e analítico. Possui uma representação gráfica, obviamente linear. Então como explorar esses aspectos na reformulação? 
A perspectiva 1 elencada acima sugere elaborar perguntas que conduzam a mais de uma resposta. Frente a isso, o problema poderia ser reescrito da seguinte maneira: Sabendo que num estacionamento há 32 rodas e que os veículos possuem duas ou quatros rodas, designados por carro e moto respectivamente, quantos veículos há no estacionamento? Algumas respostas possíveis poderiam ser: 1 carro e 14 motos, 5 carros e 6 motos, 2 carros e 12 motos, entre outras combinações.

Embora o problema não se caracterize em sua totalidade como uma tarefa de Investigação Matemática, a reformulação da pergunta permite mais de uma resposta, a saber, há 9 possíveis combinações entre carros e motos que satisfaz a pergunta. Uma sistematização simples das possibilidades de agrupamento de carros e motos de modo a preservar 32 rodas no total amplia as possibilidades de enfocar o problema. Vejamos:

\begin{tabular}{|c|c|c|c|c|c|c|c|c|c|}
\hline $\begin{array}{c}\text { Número } \\
\text { de carros }\end{array}$ & 0 & 1 & 2 & 3 & 4 & 5 & 6 & 7 & 8 \\
\hline $\begin{array}{c}\text { Número } \\
\text { de motos }\end{array}$ & 16 & 14 & 12 & 10 & 8 & 6 & 4 & 2 & 0 \\
\hline $\begin{array}{c}\text { Número } \\
\text { de rodas } \\
\text { de carro }\end{array}$ & 0 & 4 & 8 & 12 & 16 & 20 & 24 & 28 & 32 \\
\hline $\begin{array}{c}\text { Número } \\
\text { de rodas } \\
\text { de moto }\end{array}$ & 32 & 28 & 24 & 20 & 16 & 12 & 8 & 4 & 0 \\
\hline
\end{tabular}

Tabela 2: possíveis combinações de carros e motos. Fonte: os autores.

Ao analisar a tabela acima, abrem-se possibilidades de investigações que conduzem a conteúdos matemáticos não abrangidos pelo problema inicial, como por exemplo, princípio fundamental da contagem, progressões aritméticas, generalizações, equações e outros.

Considerando o que sugerem as perspectivas 5 e 9 , o problema deve ganhar a possibilidade de abrir-se às conjecturas e à generalização. Desse modo, o problema pode ser reestruturado da seguinte maneira: Sabendo que num estacionamento há 32 rodas entre carros e motos e um total de 11 veículos, é possível saber o número de carros, se soubermos o número de motos que estão no estacionamento? Se sim, expresse essa possibilidade por meio de uma relação matemática. É possível saber o número total de rodas de carro, se soubermos o número total de rodas de motos que estão no estacionamento? Se sim, expresse essa possibilidade por meio de uma relação matemática. Além disso, é possível saber o número de motos e de carros que estão no estacionamento? Se sim, quantos veículos de cada tipo estão no estacionamento?

Note que as possibilidades em termos de exploração já se ampliaram nesta maneira de 
enunciá-lo. Enquanto que inicialmente havia a possibilidade de trabalhar conceitos de equação com duas incógnitas e sistemas de equações lineares com duas equações e duas incógnitas, agora, além disso, é possível explorar, mesmo que intuitivamente, o conceito de função, bem como a generalização do resultado. O problema passa a admitir mais que uma resposta e passa a ser uma tarefa exploratória.

Se o problema for apresentado de modo invertido, isto é, considerar a sua resolução como sendo o enunciado, acompanhado de um roteiro aberto, a tarefa ganha a seguinte estrutura: O quadro abaixo elucida o número de carros e motos em um estacior
de rodas dos respectivos veículos. Explore-a de acordo com o roteiro abaixo.

\begin{tabular}{|c|c|c|c|}
\hline Carros+Motos & Rodas Carros & Rodas Motos & Total de Rodas \\
\hline $1+10$ & 4 & 20 & 24 \\
\hline $2+9$ & 8 & 18 & 26 \\
\hline $3+8$ & 12 & 16 & 28 \\
\hline $4+7$ & 16 & 14 & 30 \\
\hline $5+6$ & 20 & 12 & 32 \\
\hline $6+5$ & 24 & 10 & 34 \\
\hline $7+4$ & 28 & 8 & 36 \\
\hline $8+3$ & 32 & 6 & 38 \\
\hline $9+2$ & 36 & 4 & 40 \\
\hline $10+1$ & 40 & 2 & 42 \\
\hline
\end{tabular}

a) À medida que o número de carros aumenta o que acontece com o número de rodas dos carros? E à medida que se aumenta o número de motos, o que acontece com o número de rodas das motos?

b) Há alguma relação entre o aumento do número de rodas de carros e o aumento do número de rodas de motos? Se sim, qual?

c) Por que ao diminuir o número de motos, o número total de rodas dos veículos do estacionamento continua aumentando?

d) Há alguma relação matemática que permita descobrir o número de carros e o número de motos do estacionamento, sabendo-se apenas o número total de rodas? Se sim, qual?

\section{Quadro 3: tarefa de Investigação Matemática.}

Fonte: os autores.

As perguntas sempre deixam margem para a dúvida. Não há afirmações do tipo: encontre a relação entre o aumento do número de rodas de carros e o aumento do número de rodas de motos. Se a priori pressupõe-se que há uma relação, basta encontrá-la. Porém, o modo como as perguntas são enunciadas solicita uma validação das ideias frente à situação apresentada, uma vez que pode não haver relação e isso deve ser "aferido" matematicamente. Analogamente acontece o mesmo se a relação existir.

Por fim, evitar processos demasiadamente prescritivos, retirar informações, desprover o enunciado de contextualização cotidiana e enunciar a tarefa no contexto puramente matemático, conforme sugestões $2,10,11$ e 12 , abrem um leque de exploração de conceitos matemáticos que é subjetivo ao (re)formulador. A intuição matemática, num sentido fenomenológico, reside aqui ao nível dos perfis. Conforme já mencionamos, os perfis concernem à esfera completamente subjetiva e que dificilmente pode ser comunicada ou compartilhada, admitindo- 
se a idiossincrasia que se instaura em cada tarefa.

Grosso modo, uma tarefa de Investigação Matemática quando planejada de modo a possuir poucas informações, desprovida de contextualização cotidiana e enunciada no contexto puramente matemático, possibilita que a intuição matemática de quem (re)formula ganhe espaço e não seja limitada pelo enunciado, podendo destacar vários elementos que se descortinam das tarefas. No tocante a este tipo de (re)formulação, a situação apresentada inicialmente poderia ser enunciada da seguinte maneira:

Investigue a tabela abaixo e indique suas conjecturas e conclusões:
\begin{tabular}{|c|c|c|c|}
\hline$x+y$ & & & \\
\hline $1+10$ & 4 & 20 & 24 \\
\hline $2+9$ & 8 & 18 & 26 \\
\hline $3+8$ & 12 & 16 & 28 \\
\hline $4+7$ & 16 & 14 & 30 \\
\hline $5+6$ & 20 & 12 & 32 \\
\hline $6+5$ & 24 & 10 & 34 \\
\hline $7+4$ & 28 & 8 & 36 \\
\hline $8+3$ & 32 & 6 & 38 \\
\hline $9+2$ & 36 & 4 & 40 \\
\hline $10+1$ & 40 & 2 & 42 \\
\hline
\end{tabular}

Quadro 4: tarefa de Investigação Matemática.

Fonte: os autores.

Frente a esse modo de expor a situação, as possibilidades de exploração são imprevisíveis, cabendo ao investigador abordá-la da maneira que lhe for mais conveniente. Em situações de sala de aula, o professor pode direcionar a investigação de modo a atender os objetivos traçados. Dentre as possibilidades de ensino, essa tarefa permite explorar, por exemplo, o conceito de progressão aritmética (PA) em qualquer uma das três colunas, função, equação, sistema de equação, generalização.

Em nenhuma das maneiras de (re)formulação apresentadas, encontram-se, nos enunciados da tarefa ou do roteiro, palavras que fazem alusão aos conceitos a serem abordados. Esse aspecto atende à perspectiva 3 de reformulação, a saber, evitar o uso de conceitos herméticos e específicos da área e possibilita, compreender o conceito a partir da tarefa, não solicitando que o conceito já seja sabido para então resolvê-la.

\section{Exemplo 2}

É possivel colocar um certo número de círculos dentro de um quadrado de 1 centímetro de lado, tal que a soma dos raios destes círculos seja maior que 2008 centímetros? Os círculos podem ser apenas tangentes, não vale intersecção de círculos em 2 pontos (OBMEP, 2008, p. 21). 
Este problema admite uma, e somente uma, resposta - sim ou não - as quais requerem certa exploração da situação. É, portanto uma tarefa que pode desencadear uma ação investigativa, porém o final do processo culmina em uma resposta única. Problemas deste tipo são, na verdade, "mais uma questão de camuflagem do que de exploração, mas secundariamente dá aos alunos uma primeira ideia do que é a investigação matemática" (GOLDENBERG,1999, p. 5).

Tarefas deste gênero conduzem os alunos à descoberta de uma ideia ou fato matemático muito específico. "A expectativa não é de que a investigação faça emergir algum facto ou técnica específicos - e talvez nem sequer alguma conjectura" (GOLDENBERG,1999, p. 5).

Todavia, em face daquilo que compreendemos por Investigações Matemáticas - como uma atividade que requer mais do que simplesmente explorar, conjecturar e demonstrar. Requer o fazer matemática de modo que as (re)descobertas sejam discutidas e tragam à tona um conceito, uma habilidade ou um conteúdo matemático - esta tarefa requer reformulação.

Um primeiro passo é traduzir as informações enunciadas da língua vernácula para a linguagem algébrica. Além disso, sendo o número de círculos tangentes que satisfaz a hipótese: a soma dos raios ser maior que 2008 centímetros não único, abrimos a possibilidade de dispor estes círculos inscritos no quadrado e tangentes entres eles, conforme ilustrado no quadro 7. Contudo há outras maneiras de disposição destes círculos, que inclusive podem ensejar outras investigações.

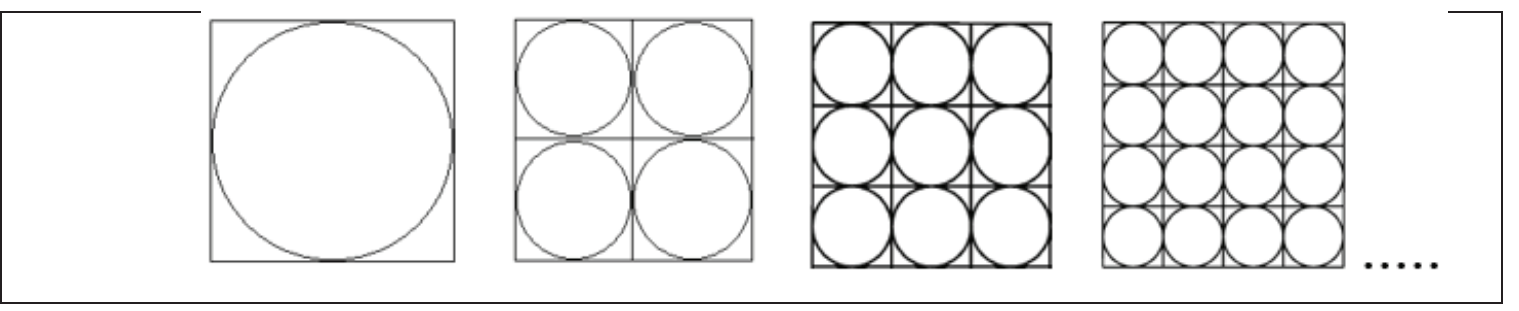

Quadro 5: possibilidade de dispor círculos tangentes em um quadrado de lado $1 \mathrm{~cm}$. Fonte: os autores.

Incialmente a descoberta pode se dar por tentativas, porém logo se perceberá que do ponto de vista operatório é impossível ilustrar a figura que fornece a resposta do problema. Desse modo o caminho mais curto é a generalização que, dentre outras possibilidades, pode ocorrer vistas ao número de círculos, à medida do lado de cada quadradinho e à medida do raio de cada círculo na enésima figura.

Uma vez que a tarefa organiza a generalização nesta sequência - número de círculos, medida do lado de cada quadradinho e medida do raio de cada círculo - ela ganha características de uma tarefa exploratória e permite responder à pergunta do problema, vejamos: 
Generalizando o número de círculos:

Note que no primeiro quadrado com um $1 \mathrm{~cm}$ de lado teremos um círculo, no segundo quadrado teremos 4 círculos, no terceiro quadrado teremos 9 círculos, no quarto quadrado teremos 16 círculos, no quinto quadrado teremos 25 círculos e assim sucessivamente, ou seja, na enésima figura, teremos $\mathrm{n}^{2}$ círculos, sendo n é a posição da figura.

Generalizando a medida do lado dos quadradinhos:

No primeiro quadrado temos que a medida do lado é $1 \mathrm{~cm}$, no segundo quadrado a medida dos lados de cada um dos dois quadradinhos é $\frac{1}{2} \mathrm{~cm}$, no terceiro quadrado temos que a medida do lado de cada quadradinho é $\frac{1}{3} \mathrm{~cm}$, portanto na enésima figura o lado de cada um dos $\mathrm{n}^{2}$ quadradinhos será de $\frac{1}{n} \mathrm{~cm}$.

Generalizando a medida do raio dos círculos:

Sabemos que a medida do raio de um círculo é a metade da medida do seu diâmetro. Dessa forma o raio do círculo contido na primeira figura será $\frac{1}{2} \mathrm{~cm}$, o raio dos círculos contidos na segunda figura será de $\frac{1}{4} \mathrm{~cm}$, na terceira figura será de $\frac{1}{8} \mathrm{~cm}$, e assim sucessivamente. Observe que o raio de cada círculo em cada figura é $\frac{1}{2} \times$ lado de cada quadradinho, assim o raio de cada círculo da enésima figura será $\frac{1}{2 n} \mathrm{~cm}$, sendo $\mathrm{n}$ é a posição que a figura ocupa.

a) Para $n=1$ temos que a soma dos raios é:

para $n=2$ temos:

$$
1 \times \frac{1}{2}=\frac{1}{2}
$$

para $n=3$ temos:

$$
2^{2} \times \frac{1}{4}=1
$$

$$
3^{2} \times \frac{1}{6}=\frac{3}{2}
$$

Respondendo o problema:

Desse modo a soma dos raios desses $n^{2}$ círculos é igual a $n^{2} \times \frac{1}{2 n}=\frac{n}{2}$. Como estamos interessados no caso desta soma ser maior que 2008, devemos ter $\frac{n}{2}>2008$, ou seja, $n>4016$. Logo dividindo o quadrado em mais de 4017 quadradinhos, a soma dos raios dos círculos será maior que 2008.

Quadro 6: possibilidade exploração do problema 1

Fonte: adaptado de Wichnoski (2012)

Embora a resolução apresentada imponha certo grau de dificuldade, quando superado vai somente cumprir o objetivo de dizer se é possível colocar um certo número de círculos tangentes dentro de um quadrado de 1 centímetro de lado, tal que a soma dos raios destes círculos seja maior que 2008 centímetros, ou não; e a partir de quantos círculos isso é possível.

Do ponto de vista do ensino isto é rudimentar, pois a tarefa possibilita apenas a exploração da situação. Os ganhos se resumem ao desenvolvimento da técnica de generalização, que possui sua importância na construção do conhecimento matemático, porém é incipiente do ponto de vista do ensino dos seus conteúdos.

Atendendo a sugestão 5 - estabelecer perguntas que permitam a construção de conjecturas 
- há a possibilidade de efetuar variações utilizando, por exemplo, perguntas do tipo: e se o lado do quadrado for aumentado para $2 \mathrm{~cm}$, para $3 \mathrm{~cm}$, para...? E se mudar a disposição dos círculos? E se..., e se...; isto vai potencializar as formas de investigar a tarefa e consequentemente de conjecturar sobre ela.

Outra alternativa é modificar o problema de modo a ensejar outras investigações que busquem não apenas respondê-lo, mas que em decorrência do processo investigativo possam emergir possibilidades de ensino dos conteúdos matemáticos. $\mathrm{Na}$ tentativa de cumprir este objetivo, a sequência de figuras do quadro 7 , pode ser desprovida do enunciado, conforme a sugestão 11 de reformulação e ser investigada do ponto de vista da área entre as circunferências, limitada pelo quadrado.

Este modo de abordar a tarefa abre, por exemplo, a possibilidade de trabalhar o conceito de limite no infinito ${ }^{4}$, ou seja, possibilita tratar o conteúdo matemático durante o desenvolvimento da atividade. Este aspecto é salutar e do nosso ponto de vista deve ser valorizado em tarefas de Investigação Matemática, caso contrário elas se resumem a problemas de exploração. A fim de esclarecer o leitor sobre esta possibilidade, o quadro abaixo apresenta a reformulação do problema do exemplo 2 .

Observe a sequência de figuras abaixo e investigue quanto a área entre as circunferências e limitada pelo quadrado maior. Os quadrados maiores possuem $1 \mathrm{~cm}$ de lado.
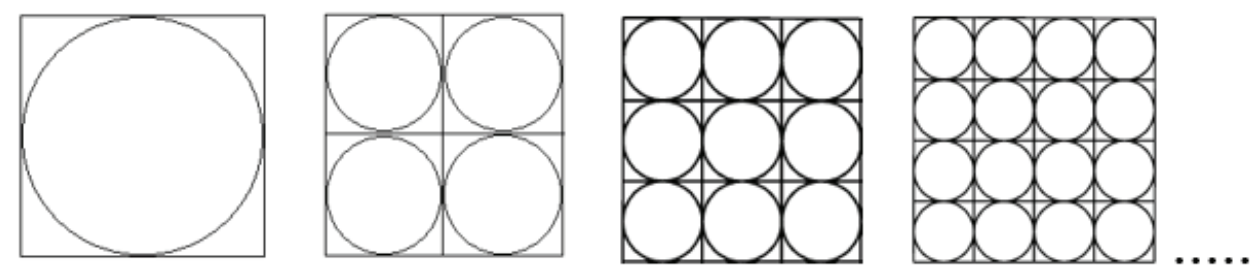

Desenvolvimento:

Note que a área limitada pelo quadrado maior e entre as circunferências é dada pela diferença entre a área do quadrado e a área da circunferência (na primeira figura) e pela diferença da área do quadro maior e da soma das áreas das circunferências (nas demais figuras). Sendo $n$ a posição que a figura ocupa temos que a área é dada por $A=1-A_{c}$, sendo $A_{c}$ área da circunferência. Assim:

$$
\begin{array}{ll}
n=1 & A=1-\pi r^{2} \rightarrow A=1-\pi \cdot\left(\frac{1}{2}\right)^{2} \rightarrow A=\frac{4-\pi}{4} \\
n=2 & A=1-\pi r^{2} \rightarrow A=1-4 \pi \cdot\left(\frac{1}{4}\right)^{2} \rightarrow A=1-\frac{4 \pi}{16} \rightarrow A=\frac{4-\pi}{4} \\
n=3 & A=1-\pi r^{2} \rightarrow A=1-9 \pi \cdot\left(\frac{1}{2}\right)^{2} \rightarrow A=1-\frac{9 \pi}{36} \rightarrow A=\frac{4-\pi}{4} \\
\vdots & \\
n=k & A=1-\pi r^{2} \rightarrow A=1-k^{2} \pi \cdot\left(\frac{1}{2 k}\right)^{2} \rightarrow A=1-\frac{k^{2} \pi}{4 k^{2}} \rightarrow A=\frac{4-\pi}{4}
\end{array}
$$

${ }^{4}$ A definição formal matemática deste conceito é: Dizemos que $\lim _{x \rightarrow \infty} f(x)=L$ se para todo $\varepsilon>0$ existe $N>0$ tal que vale a implicação $x>N \Rightarrow|f(x)-L|<\varepsilon$ 
Portanto, na k-ésima posição a área limitada pelo quadrado maior e entre as circunferências é dada pela expressão

e usando a ideia de limite segue que

$$
A=1-\frac{k^{2} \pi}{4 k^{2}}
$$

$$
\lim _{n \rightarrow \infty}\left(1-\frac{k^{2} \pi}{4 k^{2}}\right)=\frac{4-\pi}{4} \approx 0.2146 \mathrm{~cm}^{2}
$$

Quadro 7: possibilidade de reformulação e exploração do problema 1.

Fonte: os autores.

Desse modo, o problema que inicialmente tinha como objetivo uma resposta única, via processo de generalização, se (re)configura e se abre à investigação com uma riqueza de conteúdos matemáticos a serem ensinados como, por exemplo, limite, função, área de figuras quadradas, área de circunferência, além de servir de aporte para a técnica de demonstração por indução.

Outro aspecto possível e interessante de ser investigado com esta tarefa é o fato de a área entre as circunferências e limitada pelo quadrado maior se manter constante, independentemente da posição da figura.

\section{Considerações}

Em geral os problemas matemáticos veiculados nas escolas são problemas que conduzem a uma única resposta ou a múltiplas respostas previamente sabidas. Essa visão reforça a ideia de que a matemática é uma ciência em que tudo se encaixa perfeitamente. Sem dúvida, ela possui uma estabilidade em termos de resultados, mas somente em termos de resultados e não em termos de construção e processo, portanto, é epistemologicamente não linear.

Em face disso é que se impõe a necessidade de direcionar o ensino para a construção e o processo desencadeado diante das tarefas matemáticas, papel que se propunha a Investigação Matemática. Porém, tarefas construídas nesta perspectiva não são corriqueiras nos materiais didáticos de apoio ao professor e, talvez, esse seja um dos motivos que impede o avanço do ensino de matemática pautado nessa perspectiva. As possibilidades de (re)formulação elencadas acima, buscam minimizar este cenário e se prestam, além de possibilidades de ensino, como um parâmetro ao professor que se pretende (re)formulador.

$\mathrm{Na}$ busca dos aspectos que contribuem para a (re)formulação de tarefas de matemática em tarefas de Investigação Matemática, alguns encaminhamentos revelaram-se mais ou menos 
estáveis e, em certo sentido, essenciais. Dentre eles elencamos: desprover o enunciado de informações, fomentar as perguntas e conjecturas, inverter a ordem do problema inicial, evitar prescrições demasiadamente diretivas e evitar o uso de conceitos herméticos e específicos da área.

Tarefas enunciadas em cenários reais ou semirreais (SKOVSMOSE, 2000) parecem se configurar em um obstáculo epistemológico ou em sentido lakatosiano (1978) como uma anomalia na teoria da Investigação Matemática. Uma possibilidade de contornar este empasse é enunciar a tarefa no contexto puramente matemático, conforme a sugestão 12. Esta caraterística já foi apontada por Ponte et al. (1998), Wichnoski (2016) e nos parece que o exemplo 1 vem reforçá-la.

Outra questão que merece atenção é a possibilidade de incrementar às tarefas de Investigação Matemática roteiros abertos ou semiabertos. É necessário preservar um nível mínimo de abertura, porém em se tratando de ambientes escolares, roteiros demasiadamente abertos fazem com que os alunos não familiarizados se sintam perdidos e logo esmoreçam na atividade. Além disso, o professor pode acabar se perdendo durante a aula devido a insegurança sentida e atribuída ao fato de que "tudo pode acontecer", dada as possibilidades que, embora salutares do ponto de vista teórico da Investigação Matemática, podem divagar do objetivo pensado a priori.

Mesmo que as Investigações Matemáticas, em tese, se apresentam como propostas que permitem certa liberdade de inquirição, é preciso, paradoxalmente, impor certo grau de restrição para que as ideias emergentes, ainda que diferentes, convirjam para o objetivo da aula. Se porventura o professor se utilizar do exemplo 1 deste trabalho para ensinar o conteúdo de progressão aritmética (PA), haverá, conforme já mencionamos, a possibilidade de emergirem ideias que conduzam ao conteúdo de função, equação e sistemas de equações.

Essa possibilidade não é pejorativa, dado que é esta pluralidade dos conteúdos matemáticos imbricados em uma única tarefa que faz com que a Investigação Matemática seja uma perspectiva em potencial para a sala de aula. Contudo, em situações práticas, essas possibilidades devem ser direcionadas via roteiros semiabertos ou pela postura do professor. Os roteiros abertos podem ser utilizados se tanto o professor quanto os alunos estiverem habituados com o trabalho investigativo ou se estiverem abertos a esse tipo de trabalho por serem arrojados e exploradores.

A concluir, reiteramos que as perspectivas de (re)formulações apresentadas não são únicas e se constituem em diretrizes na (re)formulação de tarefas de Investigação Matemática, tendo 
como principal objetivo nortear esse processo e não o delinear.

\section{Referências}

BUTTS, Thomas. Formulando problemas adequadamente. In: KRULIK, S.; REYS, R. E.; (Org). A resolução de problemas na matemática escolar. São Paulo: Atual, 1997, p. 32-48.

GOLDENBERG, E. Paul. Quatro funções da investigação na aula de Matemática. In P. Abrantes, J. P. Ponte, H. Fonseca, \& L. Brunheira (Eds.), Investigações matemáticas na aula e no currículo. Lisboa: APM e Projecto MPT.

GRAVINA, Maria Alice; SANTAROSA, Lucila Maria Costi. A Aprendizagem Matemática em Ambientes Informatizados. Informática na Educação: teoria e prática. Porto Alegre, v. 2, n. 1, mai. 1999.

JUNKERFEURBOM, Maiara Aline.; KLÜBER, Tiago Emanuel. Tarefas de Investigação Matemática em Livros Didáticos do $8^{\circ}$ Ano Aprovados pelo Programa Nacional do Livro Didático - PNLD (2014). Educação Matemática em Revista, Brasília, v. 22, n. 55, p.7-16, jul./set. 2017.

LAKATOS, Imre. História da Ciência e Suas Reconstruções Racionais. Lisboa, 1978.

OBMEP. 2008. Disponível em:

$<$ http://www.oei.es/historico/cienciayuniversidad/spip.php?article161>. Acesso: 20/12/2017.

PINHEIRO, José Milton Lopes. A Aprendizagem Significativa em Ambientes Colaborativoinvestigativos de Aprendizagem: Um Estudo De Conceitos De Geometria Analítica Plana. 2013. 202 f. Dissertação (Mestrado) - Programa de Mestrado Profissional em Educação Matemática, UFJF, Juiz de Fora, 2013.

PONTE, João Pedro da. Investigar, Ensinar e Aprender. Actas do ProfMat (CD-ROM, p.25-39). Lisboa: APM, 2003.

PONTE, João Pedro da; BROCARDO, Joana; OLIVEIRA, Hélia. Investigações Matemáticas na sala de Aula. 3 ed. Belo Horizonte: Autêntica, 2013.

SOKOLOWSKI, R. Introdução à fenomenologia. (Trad.) Alfredo de Oliveira Moraes. São Paulo: Loyola, 2004.

VINCH, Evandro Martins; WICHNOSKI, Paulo; SANTOS, Marcos Willian da Silva. Investigação Matemática: uma prática em sala de aula. In: Anais... Simpósio Nacional de Ensino e Aprendizagem, 3, 2016. Disponível em: < http://www.utfpr.edu.br/londrina/cursos/mestrados-doutorados/Ofertadosneste-Campus/mestrado-profissional-em-ensino-de-ciencias-humanas-sociais-e-danatureza/documentos/Anais_III_SEA_artigo_MIOLOCOMPLETO.pdf >. Acesso em 30/01/2018.

WICHNOSKI, P. KLÜBER, T. E. Um olhar Lakatosiano sobre a tendência investigação matemática. Revemat. Florianópolis (SC), v.10, n. 1, p. 65-80, 2015. 